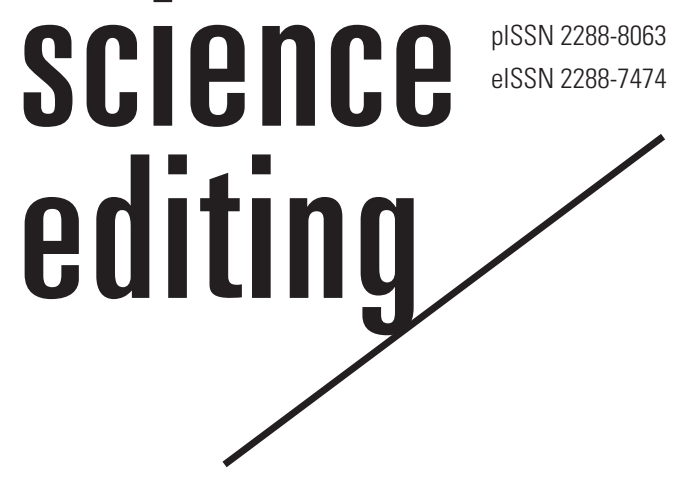

\title{
Bibliometric and content analysis of medical articles in the PubMed database published by North Korean authors from 1997 to July 2017
}

\author{
Geum Hee Jeong ${ }^{1}$, Sun Huh ${ }^{2}$ \\ 'Division of Nursing, Hallym University, Chuncheon; ${ }^{2}$ Department of Parasitology and Institute of Medical Education, College of
} Medicine, Hallym University, Chuncheon, Korea

\begin{abstract}
This study aimed at analyzing the bibliometric characteristics and content of medical articles from North Korea in PubMed and characterizing the patterns of international cooperation of medical researchers in North Korea. We hypothesized that the number of publications from North Korea in PubMed has increased recently as a result of active cooperation with foreign researchers. PubMed was searched on July 19, 2017 using the search term "(North Korea [Affiliation]) OR Democratic People's Republic of Korea [Affiliation]) OR DPRK [Affiliation]." The content of medical articles was analyzed and cooperative work with foreign researchers was noted. The number of medical articles in PubMed through July 2017 was 16, of which 2 were by North Korean authors only. From the content of these articles, it was found that researchers in top-notch institutions, including Kim Il Sung University, can access the internet, and that a dental caries prevention program supported by Finland has been in place for more than 10 years. The number of publications from North Korea in PubMed has increased recently, although the amount is still very small. Providing internet access to North Korean researchers will accelerate their submissions to international journals.
\end{abstract}

Keywords

Democratic People's Republic of Korea; International cooperation; Internet; Publications; PubMed

Correspondence to Sun Huh shuh@hallym.ac.kr

ORCID

Geum Hee Jeong

http://orcid.org/0000-0002-2254-1962 Sun Huh

http://orcid.org/0000-0002-8559-8640\#

\section{Introduction}

What is the content of medical science in North Korea? It is difficult to know exactly because there is no accessible information on medical science in North Korea. The important vital statistics on North Korea are as follows. In 2015, the neonatal mortality rate (per 1,000 live births) 
was 13.5 , the maternal mortality ratio (per 100,000 live births) was 82 , the life expectancy of males was 67.0 years, and that of females was 74.0 years, according to the 2017 World Health Statistics published by the World Health Organization [1]. The above data can be compared to the corresponding figures from South Korea: neonatal mortality rate, 1.6; maternal mortality ratio, 11.0; and life expectancy of males and females, 78.8 years and 85.5 years, respectively. This comparison indicates that medical health services in North Korea cannot be considered to be of high quality, although some indices have shown improvement (Fig. 1). It is difficult to obtain information on the status of medical science in North Korea, since medical journals from North Korea are not actively circulated throughout the world. Recently, NK Scholar was constructed with the support of the Korean government. It is available at http://www.nkscholar.com, and contains scientific, technological, and medical journals, including 9 medical journals. However, the interface of this database is only in Korean, making it difficult to search if the user cannot understand Korean. An article was published on the 1950s-era North Korean medical journal entitled In-Min-Bo-Gun (Health of the People), which was the official journal of the Ministry of Health, North Korea. The aim of In-Min-Bo-Gun was to give all medical health personnel strong incentives to implement the public health policies of the North Korean government after the Korean War [2]. On July 1, 2016, a content analysis of Naegwaji (North Korea Journal of Internal Medicine) was presented at the spring conference of Tongilbogonuuiryohakhoi (Korean Academy of Unification Medical Health, http://www.ahku. $\mathrm{kr} /$ ) [3]. A total of 2092 articles from 2006 to 2015 were reviewed, with major subject categories including gastroenterology $(25 \%)$, the circulatory system (15\%), the respiratory system (9\%), and endocrinology (5\%). In gastroenterology, topics of high frequency were upper gastrointestinal diseases, liver diseases, and biliary diseases. For the circulatory system,

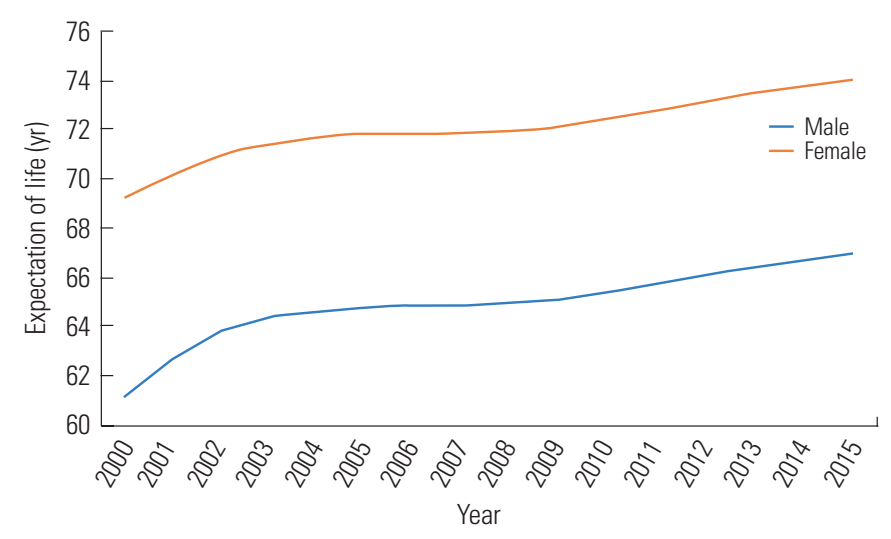

Fig. 1. Life expectancy at birth in North Korea from 2000 to 2015. hypertension, hypercholesterolemia, and heart failure were major topics. For the respiratory system, infectious diseases, chronic obstructive pulmonary disease, asthma, and carbon monoxide intoxication were common topics. In endocrinology, diabetes was the top-ranking topic. Regarding experimental studies, well-known medicines, herbal medicine, and folk remedies were common topics. A bibliometric analysis was published of articles from North Korea indexed in the Science Citation Index Expanded; however, it did not provide content analysis of the medical articles, but instead provided the categories of the articles: microbiology, 9; pharmacology and pharmacy, 8; genetic heredity, 6; and so on [4]. In another analysis of the scientific collaboration of North Korean researchers by Shelton, of 297 articles from the Web of Science, 5\% from 1976 to 2001 and 6\% from 2001 to 2011 were from the field of clinical medicine [5].

Another way of examining the content of medical science in North Korea is to search articles available through PubMed (https://www.ncbi.nlm.nih.gov/pubmed/). The present study aimed at analyzing the bibliometric characteristics and content of medical articles by North Korean researchers in PubMed and characterizing the patterns of international cooperation of medical researchers in North Korea. We hypothesized that the number of publications from North Korea in PubMed has increased recently as a result of active cooperation with foreign researchers.

\section{Methods}

PubMed was searched on July 19, 2017 using the search term "(North Korea [Affiliation]) OR Democratic People's Republic of Korea [Affiliation]) OR DPRK [Affiliation].” The search results were moved to a text file, and the article title, journal title, year of publication, digital object identifier (DOI), name of the North Korean authors, affiliation of the North Korean authors, affiliation of the co-authors outside of North Korea, co-authors' country, topics, and fields were entered. If the country's name was erroneously described as North Korea (Democratic People's Republic of Korea), the corresponding articles were removed before being entered. The bibliometric characteristics and content of articles in the medical field were analyzed and cooperative work with foreign researchers was noted.

\section{Results}

The search yielded a total of 44 results, of which 32 articles were from North Korea (Suppl. 1). Twelve articles were from South Korea or Spain, with the country of affiliation mistyped by the publisher. Of the 32 articles from North Korea, 16 were 


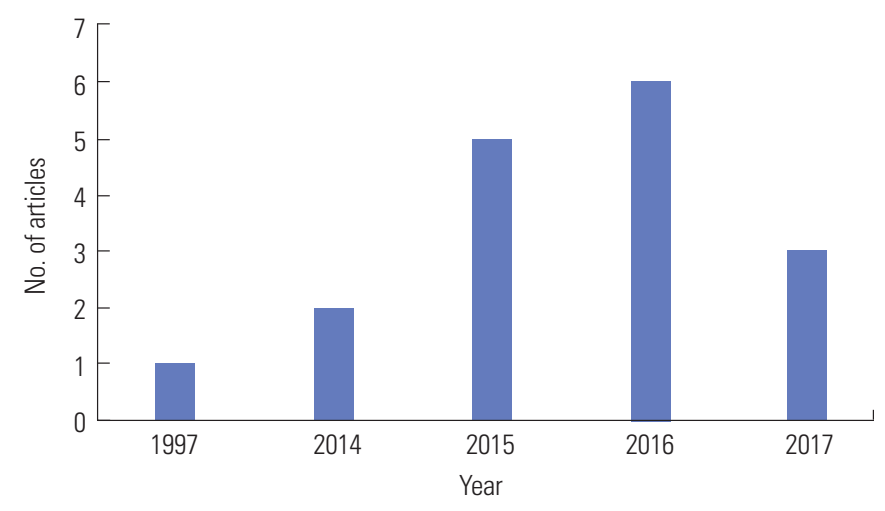

Fig. 2. Number of articles in PubMed from North Korea according to year.

in the medical field. The remaining 16 articles fell into the domains of natural sciences (5), engineering (4), and agriculture and fisheries (7). The number of articles by year is shown in Fig. 2. The number of articles began to increase in 2014, although the amount is still low. No journals were predominant, although 8 articles were published in journals by Elsevier, with the DOI prefix of 10.1016. Two were from journals by John Wiley \& Sons, with the DOI prefix of 10.1111 (Suppl. 1). The most commonly published author was ChunSik Choe from Kim Il Sung University with 3 dermatology articles, which were all cooperative work with researchers from Charité-Universitätsmedizin Berlin, Germany. He used confocal Raman microscopy to measure the penetration of a variety of oils, caffeine, and propylene glycol [6-8]. It is assumed that he visits Germany to engage in cooperative work. Eight of the 16 articles were written by researchers from Kim Il Sung University, and 2 articles were from the Korea Education Fund. As for the co-authors' countries, 6 were from China, 3 from Finland and Germany each, and 2 were from the United States.

Three of the articles were on dermatology, as mentioned with regard to the work of Chun Sik Choe. There were 3 articles on dentistry. Those works were supported by the Finnish Development Cooperation Organization (FIDA) International. The Children's Oral Health Promotion Program was launched and some of its results were published: "The decrease in dental caries may be partly due to the exfoliation of deciduous teeth and dental treatment received. However, the study gave some reference emphasizing the early starting of the prevention" [9]; "After a preventive program, most of the children reported brushing their teeth at least twice a day, using fluoride toothpaste and drinking water for thirst but frequent sweet snacking was common" [10]; and "The occurrence of dental caries associated statistically significantly with the frequency of sweet snacking but not with the frequency of tooth brushing or the use of water for thirst instead of sugary beverages" [11]. One review article on the global vaccine supply was written by a Chinese researcher who worked in Pyongyang, the capital of North Korea, as a vaccine consultant. He mentioned that an increased production of vaccines and delivery in less developed countries resulted a dramatic decreases in childhood morbidity and mortality around the world [12]. A meta-analysis was published on the risk factors for otitis media with effusion, allergic rhinitis, and allergy [13]. There was one parasitology article, with the following findings: "60,1013 vivax malaria cases reported during 1999 to 2001. In 2002, mass primaquine preventive treatment (MPPT) that prescribed a daily primaquine dose of $0.25 \mathrm{mg} / \mathrm{kg}$ was administered after breakfast for 14 consecutive days to healthy people, after confirming its effect to prevent malaria infection in pilot studies which was supported by World Health Organization. MPPT has been executed up to now; however, inadequate resources interrupted MPPT in 2008, 2011 and 2012, so that an increase in malaria cases was observed in each of these years" [14].

An algorithm for the automatic diagnosis of malignant nodules was proposed based on the simple linear iterative clustering super-pixels method to segment pulmonary regions from chest computerized tomography $(\mathrm{CT})$ images and the level-set model to extract pulmonary nodules that assume the shape of the pulmonary nodules as sphere-like contour regions. This was an application of a mathematical model to radiology [15]. An article on the history of neurosurgery in North Korea was a very rare article on medical history in North Korea:

"After Korean War in 1953, Romanian neurosurgeon visited North Korea and began to train North Korean surgeon. After that, there had been continuous relationship between Romania and North Korea for the exchange of neurosurgeons. Recently, there was a dispatch of neurosurgeon to other countries such as Germany, Vietnam, Japan and India for being trained. Also the neurosurgeons from Unites States continuously visited Pyongyang to train North Korean counterparts. Currently, three magnetic resonance imaging scanners and seven CT scanners were in Pyongyang. With the possible exception of some hospitals in the Special Economic Zone City of Rason, the hospitals outside Pyongyang do not have $\mathrm{CT}$ or magnetic resonance imaging. The big problem is the way of information exchange. Because it is difficult to use fax or email, the direct contact is the only way to learn the new technique or knowledge" [16].

There were 2 articles by only North Korean authors. One was about the tissue culture of herbal medicine. Clonal mass propagation to obtain mountainous sources of Rheum coreanum Nakai, a rare medicinal plant in North Korea, was established by rhizome tissue culture [17]. The other dealt with the "comparison of the clinical efficacy of the new bougie-internal 
urethrectomy with internal urethrotomy and urethroplasty to treat urethral stricture disease." It suggested a new tool for the treatment of urologic disease [18]. The former was published in the Saudi Journal of Biological Sciences in 2016 and the latter was published in the Canadian Urological Association Journal in 2015. Both journals are open-access journals deposited in PubMed Central.

\section{Discussion}

We can find the literature that presented a network analysis of co-authors and keywords in Yebanguihak (North Korean Journal of Preventive Medicine). The major article keywords were 'experiment-based bacterial detection,' 'sustainable immune system,' and 'prevention of infection.' The co-author analysis showed centralized trends with one-time events or segmented patterns. Additionally, some specific researchers exerted significant influence [19]. In the present study, this kind of network analysis was not done because only 16 articles were analyzed. There were no predominant researchers except for Chun Sik Choe from Kim Il Sung University. The predominant affiliation was Kim Il Sung University, from which half of the articles were published. This phenomenon has been observed across all scientific fields [4]. Although there were no dominant journals, journals from Elsevier (8) were the most common.

Interesting epidemiological data were presented on the prevention of dental caries in research that stressed the importance of early interventions for dental health by the public or government. If the support from FIDA International continues, there may be more articles in PubMed on preventive or therapeutic measures taken against dental caries among North Korean children. An article on malaria mass treatment indicated that there was a lack of medicine due to economic problems in North Korea. Because the annual incidence of vivax malaria in South Korea is believed to be caused by mosquitoes from North Korea, the malaria epidemic in North Korea has affected malaria incidence in South Korea [20]. If continuous South Korean government support is provided for the MPPT program, it may be able to prevent malaria cases in North Korea. The article on the history of neurosurgery indicates to us that if tensions ease on the Korean Peninsula, information exchange between the two Koreas may become easier. Because South Korea is one of the top-notch countries in the world with regard to neurosurgical science and technology, it will be convenient for North Korean surgeons to obtain recent information and technology under such conditions.

The 2 publications by North Korean authors only in open access journals suggested that top-ranking medical research- ers working at Kim Il Sung University, the Academy of Medical Sciences, and Kim Man You Hospital can access the internet, enabling them to submit manuscripts to international journals, although most other medical researchers have difficulty in accessing the internet. They are believed to access other medical journals cited as references in their publications. Therefore, there may be a dramatic increase in the number of articles by North Korean authors only that are indexed in PubMed in the near future if the North Korean government allows most medical researchers to access the internet at any time. There were no publications in journals in South Korea by North Korean researchers. The fact that most medical journals in South Korea are open access and do not require an article processing charge is expected to provide North Korean researchers with an excellent opportunity to submit their manuscripts to journals in South Korea. Of the 256 member journals of the Korean Association of Medical Journal Editors, 199 are open access [21]. Moreover, the full text of 115 life science journals from South Korea has been deposited in PubMed Central through July 2017.

Unfortunately, there was no article in PubMed with co-authors from South Korea and North Korea. There was some cooperative research with South Koreans, but North Korean officers did not want to disclose the data. This is one reason why there are no data in PubMed on collaborations between North and South Koreans. The competency of North Korean physicians and medical scientists is known to be excellent if they work in top-notch hospitals or universities. To improve the level of medical health services and sciences would require not only economic development, but also cooperation with medical health personnels from developed countries. Because the North Korean people have the same genetic background as South Koreans, the effects of nourishment and the environment on specific diseases will be promising topics for medical research. The easing of tensions on the Korean Peninsula will provide the chance for researchers from the two Koreas to communicate with each other; furthermore, the frequency and quality of cooperative work will increase.

What is the simple way to meet articles from North Korea in PubMed? Indexing of medical journals from North Korea in Medline is the quick answer [22]. It is known that 9 medical journals are present in North Korea in 2017 [3]. If any one of them, for example, Chosŏnüihak (North Korea Medicine) is indexed in Medline, all researchers in the world will be able to read at least its abstract and bibliographic information. However, we guess that no medical editor in North Korea can apply their journals to Medline due to North Korea government's closed policy to the United States at now. The easing of tension between North Korea and the United States and the more open policy of North Korean government may make it 
possible in the future.

In conclusion, 16 medical articles by North Korean researchers were found in PubMed through 2017. Of these articles, 2 were by North Korean authors only. It was found that researchers at top-notch institutions, including Kim Il Sung University, can access the internet, and that a dental caries prevention program supported by Finland has been in place for more than 10 years. The number of publications from North Korea in PubMed has increased recently, although the amount is still very small. Providing internet access to North Korean researchers will accelerate their submissions to international journals. Furthermore, the easing of tensions on the Korean Peninsula will facilitate cooperative research between the two Koreas.

\section{Conflict of Interest}

No potential conflict of interest relevant to this article was reported.

\section{Supplementary Material}

The supplementary file is available from the Harvard Dataverse at: https://doi.org/10.7910/DVN/NLJHN5.

\section{References}

1. World Health Organization. World health statistics 2017: monitoring health for the SDGs [Internet]. Geneva: World Health Organization; 2017 [cited 2017 Jul 30]. Available from: http://www.who.int/gho/publications/world_ health_statistics/2017/en/

2. Kim OJ. An analysis of a North Korean Medical Journal: In-Min-Bo-Gun (People's Health) in 1950s. Korean J Med Hist 2002;11:165-85.

3. Kim SG. Content analysis of Naegwaji [North Korea Journal of Internal Medicine]. Paper presented at: 2016 Spring conference Tongilbogŏnŭiryohakhoi [Korean Academy of Unification Medical Health]; 2016 Jul 1; Seoul, Korea.

4. Jeong GH, Huh S. Bibliometric analysis of publications from North Korea indexed in the Web of Science Core Collection from 1988 to 2016. Sci Ed 2017;4:24-9. https:// doi.org/10.6087/kcse.85

5. Shelton RD, Lewison G. Scientific collaboration as a window and a door into North Korea. Scientometrics 2013; 97:3-11. https://dx.doi.org/10.1007/s11192-012-0946-8

6. Choe C, Schleusener J, Lademann J, Darvin ME. In vivo confocal Raman microscopic determination of depth profiles of the stratum corneum lipid organization influenced by application of various oils. J Dermatol Sci 2017;87:183-
91. https://doi.org/10.1016/j.jdermsci.2017.04.016

7. Mujica Ascencio S, Choe C, Meinke MC, et al. Confocal Raman microscopy and multivariate statistical analysis for determination of different penetration abilities of caffeine and propylene glycol applied simultaneously in a mixture on porcine skin ex vivo. Eur J Pharm Biopharm 2016;104: 51-8. https://doi.org/10.1016/j.ejpb.2016.04.018

8. Choe C, Lademann J, Darvin ME. Confocal Raman microscopy for investigating the penetration of various oils into the human skin in vivo. J Dermatol Sci 2015;79:176-8. https://doi.org/10.1016/j.jdermsci.2015.05.004

9. Tarvonen PL, Sipila K, Yang GS, Kim JK, Lamidi ML, Suominen AL. Comparison of two preventive interventions on dental caries among children in Democratic People's Republic of Korea. Int J Dent Hyg 2016;14:301-6. https:// doi.org/10.1111/idh.12209

10. Tarvonen PL, Sipila K, Ri YS, Jang JH, Kim JH, Suominen AL. Awareness of and compliance with healthy oral habits reported by children and their parents in Democratic People's Republic of Korea after a preventive programme. Acta Odontol Scand 2016;74:525-31. https://doi.org/10.1080/00 016357.2016.1214978

11. Tarvonen PL, Suominen AL, Yang GS, Ri YS, Sipila K. Association between oral health habits and dental caries among children in Pyongyang, Democratic People's Republic of Korea. Int J Dent Hyg 2016 May 26 [Epub]. https://doi.org/10.1111/idh.12230

12. Francis DP, Du YP, Precioso AR. Global vaccine supply: the increasing role of manufacturers from middle income countries. Vaccine 2014;32:5259-65. https://doi.org/10.1016/ j.vaccine.2014.07.069

13. Cheng X, Sheng H, Ma R, et al. Allergic rhinitis and allergy are risk factors for otitis media with effusion: a metaanalysis. Allergol Immunopathol (Madr) 2017;45:25-32. https://doi.org/10.1016/j.aller.2016.03.004

14. Pant SD, Chol KY, Tegegn Y, Mandal PP, Chol RK. Mass primaquine preventive treatment for control of Plasmodium vivax malaria in the Democratic People's Republic of Korea: a country success story. WHO South East Asia J Public Health 2014;3:75-80. https://doi.org/10.4103/22243151.115828

15. Zhu H, Pak CH, Song C, et al. A novel lung cancer detection algorithm for CADs based on SSP and Level Set. Technol Health Care 2017 May 26 [Epub]. https://doi.org/10.3233/ THC-171338

16. Park KB, Roh YH, Lee-Park O, Park S. History of neurosurgery in Democratic People's Republic of Korea. World Neurosurg 2015;84:855-9. https://doi.org/10.1016/j.wneu. 2015.03.020

17. Mun SC, Mun GS. Development of an efficient callus prolif- 
eration system for Rheum coreanum Nakai, a rare medicinal plant growing in Democratic People's Republic of Korea. Saudi J Biol Sci 2016;23:488-94. https://doi.org/10.1016/ j.sjbs.2015.05.017

18. Hyn CS, Jong KH, Chol CU. A report on the clinical efficacy of a new Bougie-internal urethrectomy. Can Urol Assoc J 2015;9:E447-52. https://doi.org/10.5489/cuaj.2751

19. Jung M, Chung D, Choi M. Keywords network analysis of articles in the North Korean journal of preventive medicine 1997-2006. J Prev Med Public Health 2008;41:365-72. https://doi.org/10.3961/jpmph.2008.41.6.365
20. Lee JS, Lee WJ, Cho SH, Ree HI. Outbreak of vivax malaria in areas adjacent to the demilitarized zone, South Korea, 1998. Am J Trop Med Hyg 2002;66:13-7. https://doi.org/ 10.4269/ajtmh.2002.66.13

21. Jeong GH, Huh S. Status of digital standards in Korean medical journals in 2016. Sci Ed 2016;3:100-4. https://doi. org $/ 10.6087 / \mathrm{kcse} .73$

22. Huh S. Promotion to MEDLINE, indexing with Medical Subject Headings, and open data policy for the Journal of Educational Evaluation for Health Professions. J Educ Eval Health Prof 2016;13:14. https://doi.org/10.3352/jeehp.2016.13.14 